\title{
Perforated gastric ulcer
}

\section{J. Wilson-Macdonald, N.J.McC. Mortensen and R.C.N. Williamson}

Bristol Royal Infirmary, Bristol BS2 $8 \mathrm{HW}, \mathrm{UK}$

\begin{abstract}
Summary: Thirty-four patients presenting with gastric perforation over a ten year period were studied, retrospectively. Five patients (14\%) died either as a result of delay in treatment or wrong diagnosis. In addition, 2 patients (6\%) died from postoperative complications. Twelve patients (38\%) were on potentially ulcerogenic drugs. Patients who had either simple closure of ulcers $(n=17)$ or partial gastrectomy $(n=6)$ had few symptoms at follow-up, but patients who underwent truncal vagotomy and pyloroplasty $(n=7)$ had poorer results. There were 2 recurrent ulcers following simple closure.
\end{abstract}

\section{Introduction}

Whilst there are many publications on the results of treatment for perforation of duodenal ulcer or mixed duodenal and gastric ulcer, there are few studies which examine gastric perforation alone.

The first recorded attempt to close a perforated gastric ulcer was made by Mikulicz in 1880 (Mikulicz, 1885). The operation was a failure, and it was not until 1891 that Heusner performed the first successful suture of a perforated gastric ulcer (Kirege, 1892). Keetley advocated emergency gastrectomy in 1902, and definitive surgery was widely used until Graham described a $2 \%$ mortality among his patients with duodenal perforation who underwent simple suture with an omental plug (Graham, 1937). Since then simple suture has been widely used for the treatment of both gastric and duodenal perforation. In 1957 Taylor popularised his conservative approach of gastric aspiration following peptic perforation, with an overall mortality rate of $11 \%$, at a time when the operative mortality rate was $7-8 \%$. However, the mortality rate among his 22 patients with gastric perforation was $25 \%$.

Perforation is not a common complication of gastric ulcer (Donaldson \& Jarrett, 1970) but may become more frequent, with the widespread use of anti-inflammatory drugs now implicated in the aetiology of gastric perforation (Trewby, 1980). When patients are treated non-operatively the mortality rate is high, and when the diagnosis is delayed, survival is rare (Donaldson \& Jarrett, 1970; Rees \& Thornbjarnson, 1973).

J. Wilson-Maodonald, F.R.C.S.; N.J.McC. Mortensen, M.D., F.R.C.S.; R.C.N. Williamson, M.D.; F.R.C.S.

Correspondence: N.J.Mc.C. Mortensen, University Department of Surgery, Bristol Royal Infirmary, Bristol BS2 8HW, UK

Accepted: 5 July 1984
There is still disagreement about the correct treatment for each patient and in our study no less than 6 different surgical operations were employed.

\section{Patients and methods}

Medical records for the years 1971-1980 at the Bristol Royal Infirmary were reviewed retrospectively. From a total of 282 patients with peptic ulcer perforation, 34 had gastric perforations (12\%). There was no change in the incidence of gastric perforation during the ten years reviewed. The average age of the patients was 63 y (range 22-89y). Nineteen patients were female (average age $62 \mathrm{y}$ ) and fifteen were male (average age $65 \mathrm{y})$. On reviewing the notes none had undergone further gastric surgery at our hospital. Postal questionnaires on gastrointestinal function usually used in our gastric follow-up clinic were sent out to the 22 patients still alive in August 1982, but only 8 replied to the questionnaire. The mean follow up in these 8 was $6.3 \mathrm{y}$.

\section{Results}

At presentation 12 patients had symptoms of indigestion for a year or more, and 6 of these patients had radiological evidence of a gastric ulcer (Table I). Of these, 1 patient had refused operation. Ten had symptoms for less than a year (average 6.3 weeks) and 12 had no symptoms prior to their perforation. Seventy-five percent of patients were smokers, and $75 \%$ of patients who had preoperative X-rays had free gas under the diaphragm. One patient had a gastrografin meal which surprisingly was normal.

An early diagnosis was made in 27 patients and 
Table I Patients known to have a gastric ulcer on admission

\begin{tabular}{|c|c|c|c|c|c|c|}
\hline Age & Sex & $\begin{array}{l}\text { Duration of } \\
\text { symptoms } \\
\text { (years) }\end{array}$ & Investigation & Drugs & Treatment & Results \\
\hline 72 & $\mathbf{M}$ & 8 & Barium meal & Caved S & $\begin{array}{c}\text { Billroth I } \\
\text { gastrectomy }\end{array}$ & Good \\
\hline 70 & $\mathbf{F}$ & 6 & Barium meal & $\begin{array}{c}\text { Distalgesic } \\
\text { Phenylbutazone }\end{array}$ & Simple closure & Good \\
\hline 81 & $\mathbf{M}$ & 5 & Barium meal & None & Simple closure & Died \\
\hline 69 & $\mathbf{F}$ & 2 & Barium meal & None & $\begin{array}{c}\text { Simple closure } \\
\text { (Biopsy: anaplastic } \\
\text { carcinoma) }\end{array}$ & Initially good \\
\hline 68 & $\mathbf{F}$ & 2 & $\begin{array}{l}\text { Endoscopy* } \\
\text { Barium meal }\end{array}$ & Carbenoxolone & $\begin{array}{c}\text { Billroth I } \\
\text { gastrectomy }\end{array}$ & Good \\
\hline 47 & $\mathbf{F}$ & 1 & Barium meal & Carbenoxolone & $\begin{array}{l}\text { Billroth I } \\
\text { gastrectomy }\end{array}$ & Good \\
\hline
\end{tabular}

* awaiting operation

promptly followed by operation. In 2 , the diagnosis was delayed for over $24 \mathrm{~h}$ and both died in the early postoperative period. Another 5 patients (average age 76) died. Of these, 2 had severe systemic diseases which affected the outcome. One had carcinoma of the pancreas with jaundice, the other sustained a myocardial infarction, femoral artery embolus and fatal pulmonary embolism. In 3 patients the diagnosis was made at post mortem examination.

Twenty-five patients $(68 \%)$ were already being treated with either an antacid, a diuretic or an anti-inflammatory drug. Two were taking anti-ulcer drugs, but none was taking cimetidine. Twelve patients $(35 \%)$ were taking anti-inflammatory drugs (Table II). Seven patients (20\%), 5 of them women, were taking a diuretic: frusemide 5 , spironolactone 2 , bumetamide 1 , and bendrofluazide 1 .

Of 34 cases, 16 had ulcers adjacent to the pylorus (antral ulcers) and 14 had ulcers on the lesser curve. Of the other patients, one proved to have an anaplastic carcinoma of the stomach, one had secondary carcinoma of the bronchus which had ulcerated and perforated, and one had a posterior peptic ulcer in the body of the stomach. The site of ulcer was not stated in the fourth patient, in whom no operation was performed.

\section{Simple closure}

There were 8 pre-pyloric ulcers and 9 lesser curve ulcers treated by biopsy and simple closure. All the perioperative deaths were in this group. A proportion of these patients were considered too ill to undergo extensive surgery and a simple procedure was indicated. Of the 4 patients who died, 2 had other severe disease, as discussed above. The other 2 had their operation delayed for over $24 \mathrm{~h}$.

It is interesting that both ulcer cancers were treated successfully by simple closure. Neither was suitable for $\bar{\omega}$ later definitive surgery owing to intra-abdominal spread of malignancy.

Apart from one patient who had a postoperative haematemesis which settled on conservative management, there were no other serious complications in this group. Only one patient had early return of symptoms at follow-up, and one patient had a gastric ulcer confirmed one year after operation by bariun? meal and treated medically.

\section{Truncal vagotomy and pyloroplasty}

Of 7 patients who underwent truncal vagotomy and pyloroplasty, 3 patients developed severe complications but none of these died. One developed a deep wound infection, one developed postoperative haematemesis requiring a 14 unit blood transfusion, and one had breakdown of the pyloroplasty requiring re-operation and a 25 day hospital stay.

Three patients complained of moderate to severe symptoms at early follow-up including wind, nausea, vomiting and diarrhoea. One patient was subsequently shown to have pyloric narrowing on barium meal, and another patient had 2 episodes of haematemesis

Table II Number of patients taking anti-inflammatory drugs or diuretics

\begin{tabular}{lcc}
\hline & Male & Female \\
\hline Corticosteroid & 1 & 2 \\
Non-steroidal anti-inflammatory & 2 & 5 \\
Corticosteroid + non-steroidal & 1 & 1 \\
$\begin{array}{l}\text { anti-inflammatory } \\
\text { Diuretic }\end{array}$ & 2 & 5 \\
$\quad$ Total & 6 & 13 \\
\hline
\end{tabular}


treated conservatively, although an ulcer recurrence was not proven.

\section{Billroth I and II gastrectomy}

Six patients underwent partial gastrectomy, 3 each with Billroth I and II anastomosis. There were no serious perioperative complications but 3 patients developed minor chest infections. None of these patients (average age $61 \mathrm{y}$ ) were considered severely ill before operation and none died. Early postoperative symptoms of indigestion were negligible, but one patient developed symptoms of early dumping.

\section{Pyloroplasty only}

This patient had a pre-pyloric ulcer which would have been treated by simple suture, except for the presence of pyloric stenosis. Heinecke-Mikulicz pyloroplasty was performed to include the ulcer. The patient made an uneventful recovery and was symptomless at follow-up.

\section{Discussion}

Although simple closure may be applicable to many patients with duodenal ulceration, some authors feel that it is inadequate for gastric perforation, and that definitive operation is necessary (Jordan et al., 1963; Playforth \& MacMahon, 1978; Surubej et al., 1981). Simple closure should perhaps be limited either to the elderly and debilitated, to those with a short history of indigestion and an acute ulcer, or to those who delay seeking medical treatment (Jordan et al., 1963; Skanstein \& Hoisater, 1976; Playforth \& MacMahon, 1978). On the other hand there were only 2 recurrent ulcers among the 13 patients surviving simple closure, and none of the deaths could be directly attributed to the shortcomings of the operation.

In this study all 3 patients died in whom the diagnosis was missed, and who did not come to operation. Even in gastric ulcer patients treated nonoperatively by choice, Taylor (1957) had a mortality rate of $25 \%$. A delay in the diagnosis of gastric perforation greater than $12 \mathrm{~h}$ was also associated with a higher mortality rate (Rees \& Thornbjarnson, 1973). Whilst all 4 operative deaths occurred in patients treated by simple closure, it is unlikely that these patients would have survived whatever their surgical management.

Following truncal vagotomy and pyloroplasty there were 3 serious complications, and 3 out of 7 patients had severe symptoms at follow-up. It would seem from this limited evidence that truncal vagotomy and pyloroplasty may not be the treatment of choice for perforated gastric ulcer. Duthie \& Kwong (1973) have shown in a prospective controlled trial that Billroth I partial gastrectomy gives better results than truncal vagotomy and pyloroplasty for chronic gastric ulcer treated electively and our own results confirm the satisfactory long-term outcome of Billroth I gastrectomy (Thomas et al., 1982). Where there is either a long history of ulceration or simple closure is impossible, either because of the size or the situation of the ulcer, partial gastrectomy is the treatment of choice (Jordan et al., 1963; Skanstein \& Hoisater, 1976; Playforth \& MacMahon, 1978). Whilst highly selective vagotomy may be as effective as partial gastrectomy in the elective treatment of chronic gastric ulcer (Reid et al., 1982; Dewar et al., 1983), it is technically difficult in the presence of a perforated gastric ulcer. The average duration of symptoms in our patients undergoing partial gastrectomy was $5 \mathrm{y}$. Partial gastrectomy is also the obvious choice where an ulcer cancer is suspected, but in some circumstances a perforated malignant ulcer can be managed by biopsy and simple closure, with definitive surgery at a later date. In Rees \& Thornbjarnson's series (1973) $24 \%$ of gastric perforations were malignant, compared with only $6 \%$ in this study.

Drugs have been implicated in gastric ulceration by many authors, although the association with gastric perforation is not yet established beyond doubt (Douglas \& Johnson, 1961; Doll et al., 1968; Taylor et al., 1968; Rees and Turnberg, 1980; Thompson, 1980; Trewby, 1980; Piper et al., 1981). In our study $38 \%$ of patients were taking either non-steroidal anti-inflammatory drugs, such as ibuprofen, indomethacin and aspirin, or steroids, which may mask symptoms of perforation. Jorgenson found that $18 \%$ of his patients with gastric perforation had taken anti-rheumatic drugs, and on further direct questioning of a small group of patients he found an incidence of $82 \%$ (Jorgensen, 1977). He also noted that prepyloric ulcers were more often associated with a positive history of anti-rheumatic treatment (Taylor et al., 1968; Jorgensen, 1977). Half our patients with prepyloric ulcers had taken anti-inflammatory drugs before perforation, and nearly half the women in this series (8 of 19) were

Table III Operations and early results

\begin{tabular}{lclc}
\hline & Number & Deaths & $\begin{array}{c}\text { Serious } \\
\text { compli- } \\
\text { cations }\end{array}$ \\
\hline Simple closure & $17(55 \%)$ & $4(24 \%)$ & 1 \\
Pyloroplasty only & $1(3 \%)$ & 0 & 0 \\
$\begin{array}{l}\text { Truncal vagotomy } \\
\quad \text { and pyloroplasty }\end{array}$ & $7(22 \%)$ & 0 & 3 \\
$\begin{array}{l}\text { Billroth I gastrectomy } \\
\text { Polya gastrectomy }\end{array}$ & $3(10 \%)$ & 0 & 0 \\
\hline
\end{tabular}

Note: Three patients had no operation; all three died. 
on similar medication; women may be more sensitive to the ulcerogenic properties of anti-inflammatory drugs than men (Jorgensen, 1977).

Seven patients were taking diuretics at the time of perforation. Whilst there is some evidence that spironolactone blocks the healing effect of carbenoxolone, perhaps by altering the flow of sodium and potassium ions across the mucosa of the gut (Doll et al., 1968), there is no evidence that all diuretics are implicated in gastric ulceration. Among women patients in our study $5(24 \%)$ were taking diuretics.

None of the patients was on cimetidine at presentation. Over the period studied, the incidence of perforated gastric ulcer remained steady, showing no fall following the introduction of cimetidine in 1976. Recently McKay \& McArdle demonstrated no significant reduction in the incidence of peptic perforation between 1966 and 1980 (McKay \& McArdle, 1982). In a retrospective study from $1932-69$, Rees \& Thornbjarnson (1973), found that $80 \%$ of patients

\section{References}

DEWAR, E.P., KING, R.F.G. \& JOHNSTON, D. (1983). Bile acid and lysolecithin concentrations in the stomach of patients with gastric ulcer: before operation and after treatment by highly selective vagotomy, Billroth I partial gastrectomy and truncal vagotomy and pyloroplasty. British Journal of Surgery, 70, 401.

DOLL, R., LANGMAN, M.J.S. \& SHAWDON, H.H. (1968). Treatment of gastric ulcer with carbenoxolone: antagonistic effect of spironolactone. Gut, 9, 42.

DONALDSON, G.A. \& JARRETT, F. (1970). Perforated gastroduodenal ulcer at the Massachusetts General Hospital 1952-1970. American Journal of Surgery, 120, 306.

DOUGLAS, R.A. \& JOHNSON, E.D. (1961). Aspirin and chronic ulcer. Medical Journal of Australia, 2, 893.

DUTHIE, H.L. \& KWONG, N.K. (1973). Vagotomy or gastrectomy for gastric ulcer. British Medical Journal, 4, 79.

GRAHAM, R.R. (1937). The treatment of perforated duodenal ulcers. Surgery, Gynecology and Obstetrics, 64, 235.

JORDAN, G.L., DEBAKEY, E. \& COOLEY, D.A. (1963). The role of resective therapy in the management of acute gastroduodenal perforation. American Journal of Surgery, $105,386$.

JORGENSEN, T.G. (1977). Drug consumption before perforation of a peptic ulcer. British Journal of Surgery, 64, 247.

KEETLEY, C.B. (1902). The surgery of non-malignant gastric ulcer and perforation. Lancet, i, 884.

KIREGE, H. (1892). Ein Fall von einem frei in die Bauchhohle perforirmagenergeshervr laparotomie: Naht der Perforationstelle. Heilung Berliner Klinische Wochenschrift, 29, 1244.

MCKAY, A.J. \& MCARDLE, C.S. (1982). Cimetidine and perforated peptic ulcer. British Journal of Surgery, 69, 319.

MIKULICZ, J. (1885). Ueber Lapartomie bei Magenund Darmperforation. Sammlung Klinischer Vorträge, 262, (Chir 83).

PIPER, D.W., MCINTOSH, J.H., ARIOTTI, D.E., FENTON, B.H. with perforated gastric ulcer were men, and this has fallen to $45 \%$ here and in other series (Jordan et al., 1963).

In summary, simple closure is adequate treatment for a perforated gastric ulcer in a patient who has a history of less than 3 months or who is a poor surgical risk. Billroth I partial gastrectomy is the treatment of choice in patients with a longer history and no contraindication to resection. Truncal vagotomy and pyloroplasty was a poor choice in our series, and nonoperative treatment is commonly fatal. Delay in treatment leads to increased mortality as does intercurrent illness. Anti-inflammatory drugs (probably) and diuretics (possibly) may be implicated in the aetiology of gastric perforation especially in women.

\section{Acknowledgements}

We wish to thank the consultant surgical staff of the Bristol Royal Infirmary for allowing us to study their patients.

\& MACLENNAN, R. (1981). Analgesic ingestion and chronic peptic ulcer. Gastroenterology, 80, 427.

PLAYFORTH, M.J. \& MACMAHON, M.J. (1978). The indications for simple closure of perforated duodenal ulcer. British Journal of Surgery, 65, 699.

REES, J.R. \& THORNBJARNSON, B. (1973). Perforated gastrie ulcer. American Journal of Surgery, 126, 93.

REES, W.D.W. \& TURNBERG, L. (1980). Appraisal of the effects of aspirin on the stomach. Lancet, ii, 410.

REID, D.A., DUTHIE, H.L., BRANSOM, C.J. \& JOHNSON, A.G. (1982). Late follow up of highly selective vagotomy with excision of ulcer compared with Billroth I gastrectomy for treatment of benign gastric ulcer. British Journal of Surgery, 69, 605.

SKANSTEIN, A. \& HOISATER, P.A. (1976). Perforated peptic ulcer: a comparison of long term results following partial gastric resection or simple closure. British Journal of Surgery, 63, 700.

SURUBEJ, R.M., KEVEUBE, V.A.M., WATBE, G.S.M. \& AYST, H.V. (1981). Simple closure of perforated gastric ulcer. Archives of Surgery, 116, 591.

TAYLOR, H. (1957). Guest Lecture: the nonsurgical treatment of perforated gastric ulcer. Gastroenterology, 33, 353.

TAYLOR, R.T., HUSKINSSON, E.C., WHITEHOUSE, G.H., DUDLEYHART, F. \& TRAPNELL, D.H. (1968). Gastric ulceration occurring during indomethacin therapy. British Medical Journal, iv, 734.

THOMAS, W.E.G., THOMPSON, M.H. \& WILLIAMSON, R.C.N. (1982). The long-term outcome of Billroth I partial gastrectomy for benign gastric ulcer. Annals of Surgery, $195,189$.

THOMPSON, M.R. (1980). Indomethacin and perforated duodenal ulcer. British Medical Journal, 280, 448.

TREWBY, P.N. (1980). Drug induced peptic ulcer and upper gastrointestinal bleeding. Journal of Hospital Medicine, 23, 185. 